\title{
Intrahepatic Bile Duct Cancer pT1a TNM Finding v8
}

National Cancer Institute

\section{Source}

National Cancer Institute. Intrahepatic Bile Duct Cancer pT1a TNM Finding v8. NCI Thesaurus. Code C134594.

Intrahepatic bile duct cancer with solitary tumor equal to or less than $5 \mathrm{~cm}$ without vascular invasion. (from AJCC 8th Ed.) 